\title{
Electrochemical study on the Efficiency of Curcuma extract as a green Inhibitor for Corrosion of $\alpha$ - brass in $1 \mathrm{MHCl}$
}

\author{
Hend Elsayed Gadow ${ }^{1, *}$ and Hanaa Mohamed Elabbasy ${ }^{2}$ \\ ${ }^{1}$ Higher Institute for Engineering and Technology, New Damietta, Egypt. \\ ${ }^{2}$ Misr Higher Institute for Engineering and Technology, Mansoura, Egypt. \\ *E-mail: hsgado73@gmail.com
}

doi: $10.20964 / 2017.07 .13$

Received: 12 February 2017 / Accepted: 25 April 2017 / Published: 12 June 2017

\begin{abstract}
The effect of Curcuma as a corrosion inhibitor compound for the corrosion of $\alpha$-brass in $1.0 \mathrm{M} \mathrm{HCl}$ was studied using chemical and electrochemical techniques. The inhibition effect was attributed to the adsorption of the compound on the $\alpha$-brass surface. The data obtained fit well to Freundlich and Henry adsorption isotherms. Potentiodynamic measurements indicated that; Curcuma considers a mixed-type inhibitor for $\alpha$-brass in $1.0 \mathrm{M} \mathrm{HCl}$. Curcuma was found to have high corrosion inhibition efficiency as indicated from the results of weight loss, potentiodynamic polarization, EFM and electrochemical impedance spectroscopy (EIS) measurements. AFM technique was performed and the results showed superior inhibition efficiency of Curcuma. The efficiencies obtained from all different techniques were in a good agreement, which prove the validity of these tools in the measurements of the tested inhibitor.
\end{abstract}

Keywords: $\alpha$-brass; corrosion inhibition;Curcuma; HCl;EIS; AFM;FTIR

\section{FULL TEXT}

(C) 2017 The Authors. Published by ESG (www.electrochemsci.org). This article is an open access article distributed under the terms and conditions of the Creative Commons Attribution license (http://creativecommons.org/licenses/by/4.0/). 